\title{
Imaging the uptake of nitrogen-fixing bacteria into larvae of the coral Acropora millepora
}

\author{
Kimberley A Lema ${ }^{1,2,3,4}$, Peta L Clode ${ }^{5,6}$, Matt R Kilburn ${ }^{5}$, Ruth Thornton ${ }^{7}$, Bette L Willis ${ }^{1,3}$ \\ and David G Bourne ${ }^{2,3}$ \\ ${ }^{1} A R C$ Centre of Excellence for Coral Reef Studies, and College of Marine and Environmental Sciences, James \\ Cook University, Townsville, Queensland, Australia; ${ }^{2}$ Centre for Marine Microbiology and Genetics, \\ Australian Institute of Marine Science, Townsville MC, Townsville, Queensland, Australia; ${ }^{3}$ AIMS@JCU, \\ James Cook University, Townsville, Queensland, Australia; ${ }^{4}$ IFREMER, Dyneco Pelagos, Plouzané, France; \\ ${ }^{5}$ Centre for Microscopy, Characterisation and Analysis, The University of Western Australia, Stirling Hwy, \\ Crawley, Western Australia, Australia; ${ }^{6}$ The Oceans Institute, The University of Western Australia, Stirling \\ Hwy, Crawley, Western Australia, Australia and ${ }^{7}$ School of Paediatrics and Child Heath, The University of \\ Western Australia, Stirling Hwy, Crawley, Western Australia, Australia
}

\begin{abstract}
Diazotrophic bacteria are instrumental in generating biologically usable forms of nitrogen by converting abundant dinitrogen gas $\left(\mathrm{N}_{2}\right)$ into available forms, such as ammonium. Although nitrogen is crucial for coral growth, direct observation of associations between diazotrophs and corals has previously been elusive. We applied fluorescence in situ hybridization (FISH) and nanoscale secondary ion mass spectrometry to observe the uptake of ${ }^{15} \mathrm{~N}$-enriched diazotrophic Vibrio sp. isolated from Acropora millepora into conspecific coral larvae. Incorporation of Vibrio sp. cells was observed in coral larvae after 4-h incubation with enriched bacteria. Uptake was restricted to the aboral epidermis of larvae, where Vibrio cells clustered in elongated aggregations. Other bacterial associates were also observed in epidermal areas in FISH analyses. Although the fate and role of these bacteria requires additional investigation, this study describes a powerful approach to further explore cell associations and nutritional pathways in the early life stages of the coral holobiont.
\end{abstract}

The ISME Journal (2016) 10, 1804-1808; doi:10.1038/ismej.2015.229; published online 22 December 2015

\section{Introduction}

Nitrogen is essential for growth, development and maintenance of all living cells, yet it is typically limited in nutrient-poor systems such as waters surrounding coral reefs. Consequently, symbioses with nitrogen-fixing organisms (diazotrophs) that convert the abundant gas dinitrogen $\left(\mathrm{N}_{2}\right)$ into more usable forms like ammonium $\left(\mathrm{NH}_{4}^{+}\right)$provide important supplemental sources of nitrogen. Although evidence is mounting that nitrogen-fixing bacteria are associated with corals (Shashar et al., 1994; Lesser et al., 2004, 2007; Kvennefors and Roff 2009; Olson et al., 2009; Kimes et al., 2010; Lema et al., 2012; Santos et al., 2014; Lema et al., 2014a,b), to date the location of nitrogen-fixing bacteria within coral tissues and evidence that fixed nitrogen is available to corals or their endosymbiotic

Correspondence: DG Bourne, Center for Marine Microbiology and Genetics, Australian Institute of Marine Science (AIMS), PMB 3, Townsville MC, Queensland 4810, Australia.

E-mail: d.bourne@aims.gov.au

Received 4 May 2015; revised 26 October 2015; accepted 6 November 2015; published online 22 December 2015 algae, Symbiodinium, remains elusive. Techniques such as nanoscale secondary ion mass spectrometry (NanoSIMS), which is able to map enriched stable isotope (for example, ${ }^{13} \mathrm{C},{ }^{15} \mathrm{~N}$ and so on) tracers at the cellular scale, provides a powerful tool for co-locating diazotrophs within coral tissues. When combined with fluorescence in situ hybridization (FISH), the presence and functional role(s) of bacteria within the coral host can be identified.

Rapid uptake of ammonium by the coral animal and transfer to symbiotic dinoflagellates have been demonstrated through molecular studies (Yellowlees et al., 2008; Stambler, 2011) and hypothesized to be key strategies in the nutritional economy of cnidarians that have evolved in nutrient-poor waters (Pernice et al., 2012; Kopp et al., 2013). Support for this is provided by recent work that used NanoSIMS to demonstrate ammonium assimilation from ${ }^{15} \mathrm{~N}$-labelled ammonium $\left({ }^{15} \mathrm{NH}_{4} \mathrm{Cl}\right)$ in cells of both the coral host (that is, Acropora aspera and Isopora palifera) and Symbiodinium symbionts after just 1-h incubation (Pernice et al., 2012; Pernice et al., 2014). NanoSIMS technology has also been 
used to show the incorporation and translocation of labelled ammonium $\left({ }^{15} \mathrm{NH}_{4}\right)$ originating from nitrogen-enriched cultured bacteria (Vibrio sp. and Alteromonas sp.) into coral larval tissues and associated Symbiodinium cells within $8 \mathrm{~h}$ of coral-bacterial incubations (Ceh et al., 2013). Although the latter demonstrated incorporation of labelled nitrogen from bacteria into coral and Symbiodinium cells, the presence of these bacteria in coral host tissues could not be confirmed and the capacity of these bacteria to fix dinitrogen gas was not investigated.

\section{Materials and methods}

In the present study, our goal was to observe the uptake of nitrogen-fixing bacteria (labelled with ${ }^{15} \mathrm{~N}$ ) into aposymbiotic (that is, Symbiodinium-free) larvae of the broadcast spawning coral Acropora millepora. The uptake of diazotrophs was initially identified through FISH, and the distribution of the ${ }^{15} \mathrm{~N}$ label was observed using NanoSIMS (see Supplementary Methods for details of techniques). Briefly, a nitrogen-fixing Vibrio sp. (GenBank accession number KF691569) was isolated from A. millepora juveniles and grown with $99 \%{ }^{15} \mathrm{~N}_{2}$ gas for isotopic labelling (Cambridge Isotope Laboratories Inc., Cambridge, MA, USA; gas cylinder) (Supplementary Figure S1; Supplementary
Table S2). Nitrogen-enriched bacteria $\left(1 \times 10^{6}\right.$ bacteria $\mathrm{ml}^{-1}$ ) were incubated with aposymbiotic larvae of $A$. millepora that were all at a similar developmental stage (that is, $4-5$ days after coral spawning; larvae elongated with a distinct oral pore that was not fully developed to avoid predation capacity) in six-well plates filled with $0.2 \mu \mathrm{m}$-filtered seawater ( $n=10$ larvae per well). The control treatments were: larvae incubated with unlabelled (that is, natural abundance ${ }^{15} \mathrm{~N} /{ }^{14} \mathrm{~N}$ ) Vibrio sp. cells (C1); and larvae incubated with the supernatant of sonicated ${ }^{15} \mathrm{~N}$ labelled Vibrio sp. cells (C2) (see Supplementary Materials). Swimming larvae were sampled after $4 \mathrm{~h}$ of incubation to avoid dilution of the ${ }^{15} \mathrm{~N}$ signal and fixed in $4 \%$ paraformaldehyde in filtered seawater.

\section{Results}

Bacteria within coral larvae were located using FISH probing performed on whole larvae samples, involving either an equimolar mix of the universal eubacterial EUB338 and specific Vibrio-GV probes, or a negative control non-EUB338 probe at a final concentration of $5 \mathrm{ng} \mathrm{ul}^{-1}$ (see Supplementary Materials and Supplementary Table S1 for details on probe sequence and fluorophore emission spectra). Imaging performed on whole A. millepora larvae $(n=16)$ using confocal laser scanning
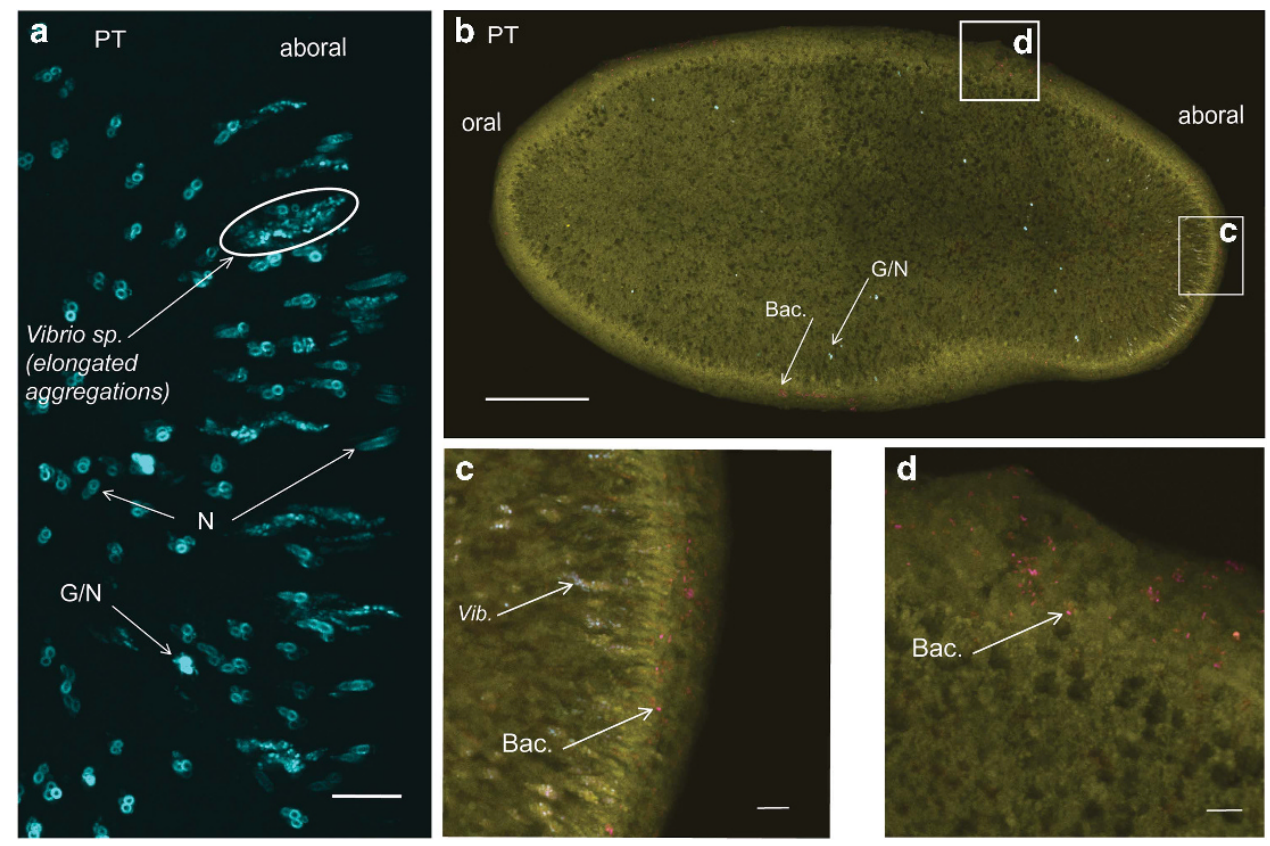

Figure 1 Maximum intensity projection confocal images of two representative 4-day old Acropora millepora larvae incubated with ${ }^{15} \mathrm{~N}$-enriched nitrogen-fixing Vibrio sp. Larval samples were hybridized with probes Vibrio-GV (ATTO647) (emits in far red laser emission channel; coloured as cyan), and EUB338 (AlexaFluor 546) (emits in orange emission channel; shown as magenta) (see Supplementary Table S2 for details on emission wavelengths). Images show: (a) aboral end of larva, identifying Vibrio sp. bacterial agglomerates (circled), unspecific binding of nematocysts (N) and possible gland cells (G); (b) larva with location of insets, where c shows Vibrio sp. (Vib.) aggregates in the aboral epidermis (cyan structures); and d shows bacterial aggregations (Bac.) in epidermis (magenta structures). PT: positive treatment (that is, larvae incubated with ${ }^{15} \mathrm{~N}$-enriched Vibrio sp. cells). Scale bars, (a) $20 \mu \mathrm{m}$, (b) $100 \mu \mathrm{m}$ and (c and d) $5 \mu \mathrm{m}$. 
microscopy (Nikon A1Si, Tokyo, Japan) and threedimensional imaging revealed elongated aggregations of bacterial cells only in the epidermal cell layer at the aboral end of the larvae (Figures 1a and c; Supplementary Figures S2). These were identified as Vibrio sp. through specific binding of the Vibriospecific probe and the general eubacterial probe (EUB338) (Supplementary Figures S2e and f). Additional bacteria (revealed by the general eubacterial probe EUB338) were also observed within coral cells. In our study, bacteria (positively labelled by probe EUB338) were located in the epidermal layer, but were found throughout the whole larvae (that is, both ends of the larvae aboral and oral, as well as middle section) (Figures $1 \mathrm{~b}-\mathrm{d}$ ).

One experimental larval sample was selected for ${ }^{15} \mathrm{~N}$ NanoSIMS analysis (Cameca NanoSIMS 50 ion microprobe, Cameca, Courbevoie, France) together with two control samples, C1 and C2. The selected samples contained Vibrio sp. aggregations, as assessed by FISH probing. NanoSIMS analyses, undertaken in the aboral epidermal regions where

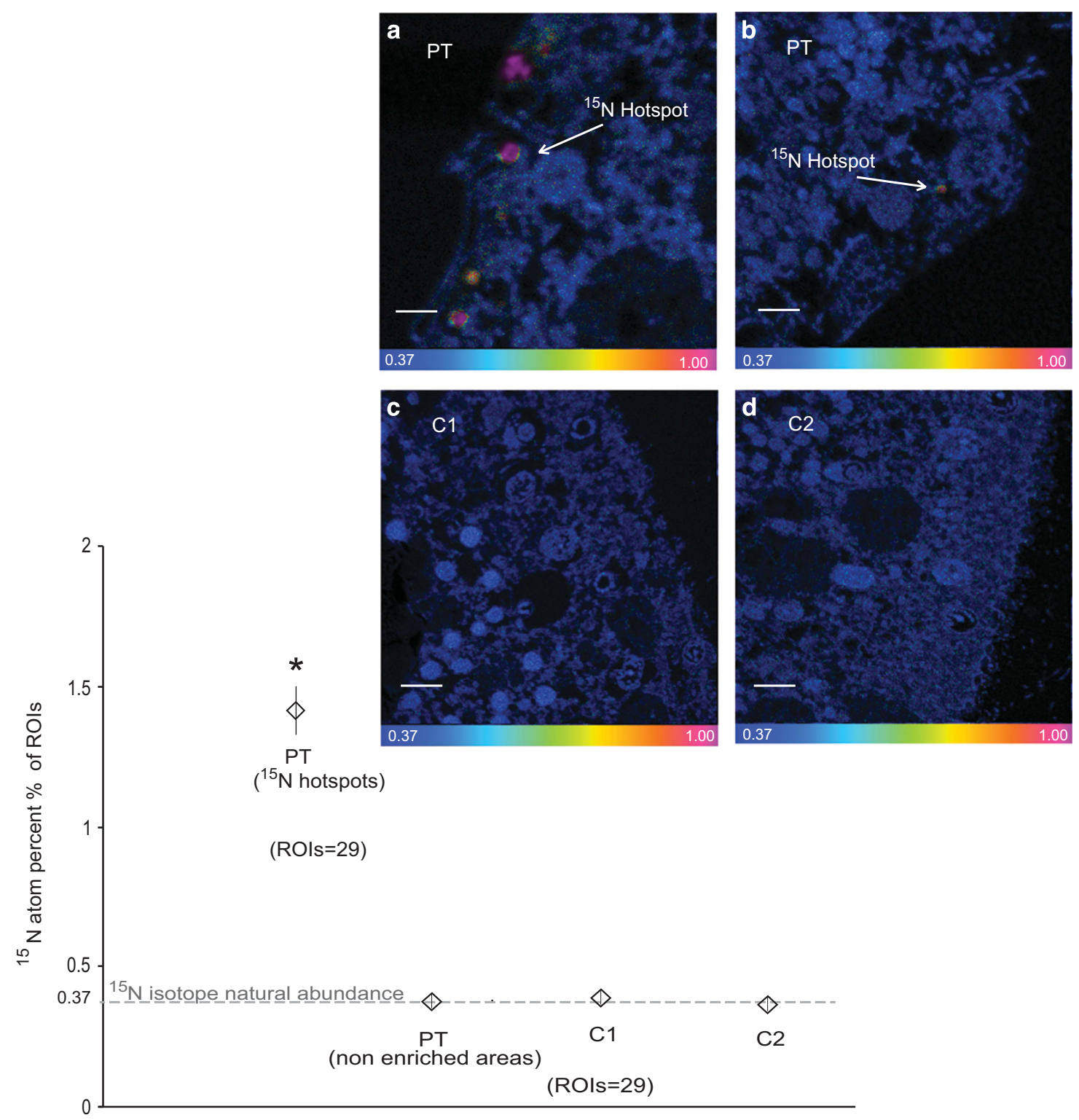

Figure 2 NanoSIMS ${ }^{15} \mathrm{~N} /{ }^{14} \mathrm{~N}$ ratio images of Acropora millepora larvae (aboral epidermis) after $4 \mathrm{~h}$ incubation with ${ }^{15} \mathrm{~N}$-enriched Vibrio sp., and a plot showing the average $(n=29)$ atom $\%$ and associated standard error from regions of interest in positive and control treatment images. The ratio is expressed as a hue saturation intensity image, where blue represents the natural isotopic abundance of nitrogen $\left({ }^{15} \mathrm{~N}\right.$ atom $\%=0.37$ ) and enrichment is shown as a shift towards magenta (colour scale label in atom \%). Dashed line indicates the natural isotopic abundance of ${ }^{15} \mathrm{~N}$ at 0.37 atom \%; asterisks $\left({ }^{*}\right)$ denote significant differences between positive samples and controls, as assessed by one-way permutational multivariate analysis of variance $(P<0.001)$. Scale bars, (a) $2 \mu \mathrm{m}$, (b), (c) and (d) $5 \mu \mathrm{m}$. PT: positive treatment (that is, larvae incubated with ${ }^{15} \mathrm{~N}$-enriched Vibrio sp. cells); C1 (control 1): larvae incubated with unlabelled Vibrio sp. cells; and C2 (control 2): larvae incubated with the surnatant of sonicated ${ }^{15} \mathrm{~N}$-enriched Vibrio sp. cells. 
Vibrio sp. aggregations were observed by FISH analysis, revealed the presence of ${ }^{15} \mathrm{~N}$-enriched hotspots $\left(1.41 \pm 0.08{ }^{15} \mathrm{~N}\right.$ atom \% levels recorded; cf. $0.37{ }^{15} \mathrm{~N}$ atom $\%$ for natural isotopic abundance), with sizes matching those of bacteria in FISH images (Figure 2; Supplementary Figures S1 and S6; Supplementary Table S2). However, no translocation of ${ }^{15} \mathrm{~N}$ could be observed into surrounding areas of larval tissue, where $\mathrm{N}$ levels $(0.377 \pm 0.001$ atom $\%)$ were close to natural abundance (Figure 2; Supplementary Table S2; Supplementary Figure S6). Similarly, in controls (C1 and C2), no ${ }^{15} \mathrm{~N}$-enriched regions were detected, and all regions of interest (that is, aboral epidermal areas) displayed $\mathrm{N}$ values close to natural abundance (C1: $0.377 \pm 0.001{ }^{15} \mathrm{~N}$ atom \%; C2: $0.379 \pm 0.001{ }^{15} \mathrm{~N}$ atom \%; Figure 2; Supplementary Table S2; Supplementary Figure S6). Differences in ${ }^{15} \mathrm{~N}$ abundance between enriched hotspots and nonenriched tissue areas, and between enriched hotspots versus controls, were statistically significant (Figure 2; Supplementary Table S2; permutational multivariate analysis of variance; $P<0.001$ ).

\section{Discussion}

This study demonstrates that aposymbiotic (that is, Symbiodinium-free) larvae of the coral A. millepora are able to uptake nitrogen-fixing bacteria (Vibrio sp.) originally isolated from conspecific coral juveniles. Both FISH and NanoSIMS analyses confirmed the presence of Vibrio sp. cells and enriched ${ }^{15} \mathrm{~N}$ hotspots, respectively, in the aboral epidermis of larvae after $4 \mathrm{~h}$ of co-incubation. Further experiments are now required to ascertain if nitrogen fixed by these bacteria is subsequently available to the coral host, as well as the subsequent fate of and extent to which this Vibrio sp. is beneficial to the coral host through nutritional supplementation. Our study provides a reliable approach to detect and observe rapid incorporation of specific bacteria into the coral holobiont and further explore nutritional pathways in the early life stages of these complex symbiotic relationships. This knowledge will advance understanding of the role bacteria have in coral larval survival, a critical stage in the resilience and success of coral reefs that face increasing anthropogenic stress.

\section{Conflict of Interest}

The authors declare no conflict of interest.

\section{Acknowledgements}

We thank Paul Rigby (UWA, CMCA) for his help in confocal instrumentation and analysis, and the Children's Clinical Research Facility at the Princess Margaret Hospital of Children for providing us their facilities that allowed FISH preparations. Rong Liu is also thanked for assistance with the NanoSIMS analysis.
This project was supported through an ANNiMS grant (Australian National Network in Marine Science) and The Australian Institute of Marine Sciences (AIMS). The authors acknowledge access to the Australian Microscopy and Microanalysis Research Facility at the Centre for Microscopy, Characterisation and Analysis, UWA, a facility funded by the University, State and Commonwealth Governments.

\section{References}

Ceh J, Kilburn MR, Cliff JB, Raina J-B, van Keulen M, Bourne DG. (2013). Nutrient cycling in early coral life stages: Pocillopora damicornis larvae provide their algal symbiont (Symbiodinium) with nitrogen acquired from bacterial associates. Ecol Evol 3: 2393-2400.

Kimes NE, Van Nostrand JD, Weil E, Zhou J, Morris PJ. (2010). Microbial functional structure of Montastraea faveolata, an important Caribbean reef-building coral, differs between healthy and yellow-band diseased colonies. Environ Microbiol 12: 541-556.

Kopp C, Pernice M, Domart-Coulon I, Djediat C, Spangenberg J, Alexander D et al. (2013). Highly dynamic cellular-level response of symbiotic coral to a sudden increase in environmental nitrogen. MBio 4: e00052-13.

Kvennefors ECE, Roff G. (2009). Evidence of cyanobacterialike endosymbionts in Acroporid corals from the Great Barrier Reef. Coral Reefs 28: 547.

Lema KA, Willis BL, Bourne DG. (2012). Corals form characteristic associations with symbiotic nitrogen-fixing bacteria. Appl Environ Microbiol 78: 3136-3144.

Lema KA, Bourne DG, Willis BL. (2014a). Onset and establishment of diazotrophs and other bacterial associates in the early life history stages of the coral Acropora millepora. Mol Ecol 23: 4682-4695.

Lema KA, Willis BL, Bourne DG. (2014b). Amplicon pyrosequencing reveals spatial and temporal consistency in diazotroph assemblages of the Acropora millepora microbiome. Environ Microbiol 16: 3345-3359.

Lesser MP, Mazel CH, Gorbunov MY, Falkowski PG. (2004). Discovery of symbiotic nitrogen-fixing cyanobacteria in corals. Science 305: 997-1000.

Lesser MP, Falcón LI, Rodríguez-Román A, Enríquez S, Hoegh-Guldberg O, Iglesias-Prieto R. (2007). Nitrogen fixation by symbiotic cyanobacteria provides a source of nitrogen for the scleractinian coral Montastraea cavernosa. Mar Ecol Prog Ser 346: 143-152.

Olson ND, Ainsworth TD, Gates RD, Takabayashi M. (2009). Diazotrophic bacteria associated with Hawaiian Montipora corals: diversity and abundance in correlation with symbiotic dinoflagellates. J Exp Mar Biol Ecol 371: 140-146.

Pernice M, Dunn SR, Tonk L, Dove S, Domart-Coulon I, Hoppe P et al. (2014). A nanoscale secondary ion mass spectrometry study of dinoflagellate functional diversity in reef-building corals. Environ Microbiol 17: 3570-3580.

Pernice M, Meibom A, Van Den Heuvel A, Kopp C, Domart-Coulon I, Hoegh-Guldberg O et al. (2012). A single-cell view of ammonium assimilation in coral-dinoflagellate symbiosis. ISME J 6: 1314-1324. 
Santos HF, Carmo FL, Duarte G, Dini-Andreote F, Castro CB, Rosado AS et al. (2014). Climate change affects key nitrogen-fixing bacterial populations on coral reefs. ISME J 8: 2272-2279.

Shashar N, Cohen Y, Loya Y, Sar N. (1994). Nitrogen fixation (acetylene reduction) in stony corals: evidence for coral-bacteria interactions. Mar Ecol Prog Ser 111: 259-264.
Stambler N. (2011). Zooxanthellae: the yellow symbionts inside animals. In: Dubinsky Z, Stambler N (eds), Coral Reefs: An Ecosystem in Transition. Springer: Netherlands, pp 87-106.

Yellowlees D, Alwyn T, Rees V, Leggat W. (2008). Metabolic interactions between algal symbionts and invertebrate hosts. Plant Cell Environ 31: 679-694.

Supplementary Information accompanies this paper on The ISME Journal website (http://www.nature.com/ismej) 